\title{
Learner-Teacher Partnership in Times of COVID-19: Community Poll Review
}

\author{
C. R. McCreadie, School of Education, University of New South Wales and Learning \\ Enhancement and Innovation, University of Adelaide, Australia.
}

Contact: Cassandra.mccreadie@adelaide.edu.au

This is not a usual "review." I am not reviewing a book or event. Instead, I am reviewing (possibly) your views as one of 103 members of the global higher education teaching and learning community dedicated to the relational praxis of engaging in learnerteacher partnerships (Matthews, 2020).

In March 2020, the World Health Organisation named COVID-19 a global pandemic. For those of us working or studying in higher education, we quickly found ourselves working and studying online while restricted in movement and physical and social contact. In educational terms, the rapid shift in mode of interacting raised significant questions for those engaged in and committed to student partnership practices. To create space for stories and experiences of partnership impacted by COVID-19, Kelly Matthews (Australia) along with some members of the IJSaP editorial board devised a "community poll" (see Matthews, Cook-Sather, Godbold, Healey, \& Rafferty, 2020), an online poll with a liveresults dashboard, to "share experiences of and approaches to engaging in pedagogical (learner-teacher) partnerships in higher education in the context of the rapid shift to online teaching and learning."

I am a Master of Higher Education student at University of New South Wales and I work at the University of Adelaide, both of which are in Australia. My research interests lie in harnessing the student lived experience as a tool for analysis rather than as a subject of analysis, hence my curiosity about the community poll. I was particularly drawn to the timing of the poll, undertaken during the height of the first wave of COVID-19 adaptations and institutional responses. In reviewing the poll responses (almost exclusively from staff yet with involvement across all continents except Antarctica), I started with a grounded, thematic approach based on Braun and Clark (2006). However, below is not summary of the poll. Rather, drawing on my multi-faceted identity, including as a current student, I bring myself into conversation with community-member responses that both illuminate and challenge assumptions about learners and teachers, including assumptions about equity and access, technological acumen, and emotional support and care in physical environments.

When asked about their partnership practices, $63 \%$ of respondents either agreed or strongly agreed that COVID-19 had disrupted their practices, and $47 \%$ either agreed or strongly agreed that under these conditions they had little time for learner-teacher partnerships (as compared with their pre-COVID-19 practices). There was also uniform agreement that these types of practices and relationships had taken on new meaning in a global pandemic environment (whether that be positive or negative), with many 
respondents positively surprised by the opportunities that the rapid shift to online had provided them.

Approximately half of the respondents considered the pedagogical student-teacher partnership to be important/essential to teaching. Not everyone explained this opinion, with many only reiterating the pedagogical value of partnerships generally, but when they did, reasons clustered around:

1. the ability to understand student context and responses to learning in the new environment and

2. creating supportive environments and strong interpersonal connections.

The majority of respondents perceived the most significant change to their practice was their attention to the redistribution of emotional support and engagement with students, as one response demonstrates:

Lots more virtual meetings but also lots more naming of dynamics and practices that might otherwise be assumed or simply go unnamed ... but having to be intentional about all of these things can make us more aware and intentional in general.

Where in the face-to-face environment pastoral care and support had been intuitively provided by literally being in the room, within the online environment, to ensure equivalence of experience, these previously tacit aspects of communication and support have been made explicit. I would be interested to see this aspect of the data explored from a student lived-experience perspective-is being in the room enough, or, as with my experience, are these new explicit practices online better?

Interestingly the concept of the "digital native" was specifically raised, and others indicated an assumption/expectation that students are more experienced and comfortable participating in the digital world than others, with some explicitly stating that students are more experienced than teachers. I am not certain that it is a useful assumption in the current context. To assume that students have more experience in the digital educational environment or that they are uniformly more comfortable with education-based technology and engagement methods because they are younger and have grown up with technology integrated within their day-to-day life is misleading, assumes all students are of a particular age group, and heightens unsustainable expectations, as noted by one respondent:

the students who are relatively new to working online are (understandably) more demanding. They are anxious; expect immediate responses 24/7; critical of set learning tasks; presenting excuses NOT to do the learning or submit assessments on time, and more. ... I have had to avoid making assumptions around technology access and confidence.

Additionally, this assumption explicitly disguises and underplays the important socioeconomic advantages necessary for students to meet this expectation. Interestingly, many respondents were surprised by the socioeconomic and social issues that the shift to fully online made explicit for them. One respondent noted "equity issues with learners who 
do not have a safe space for learning at home." Another commented: "Many non-trad students don't have access to technology."

I echo the person who wrote: "we cannot assume anything about the student learning experience at this time." The poll provides us with a good starting point for exploring the innovations and responses to the opportunities and challenges brought to higher education by the conditions of COVID-19. Yet, it also clearly shows that even for those with an interest in the inclusion of student voices within formal education, there remain significant assumptions about students and behaviours that teachers continue to carry with them which should be explored rather than assumed.

That is my review. Read the poll results at

https://www.surveymonkey.com/stories/SM-RTB68869/ or do your own analysis (see Matthews, 2020). What assumptions do you recognise? What resonates with you?

\section{ACKNOWLEDGEMENTS}

Thank you to Associate Professor Kelly Matthews for her support and encouragement throughout the development process. Also to the people who volunteered their time, wisdom, and insights in their responses to the community poll.

\section{NOTES ON CONTRIBUTORS}

C. R. McCreadie is a Master of Higher Education student at the University of New South Wales and is employed as a learning designer at the University of Adelaide. She has a research interest in the ability of student's lived experience to be used as a tool for analysis rather than as only a subject of analysis.

\section{REFERENCES}

Braun, V., \& Clarke, V. (2006). Using thematic analysis in psychology. Qualitative research in psychology, 3(2), 77-101.

Matthews, K. E. (2020). Dataset: Learner-teacher partnership in times of COVID-19: A community poll to share practices and perspectives, 4 April to 1 May 2020 [Online poll results]. Brisbane: University of Queensland. Retrieved from https://espace.library.uq.edu.au/view/UQ:9ccf895

Matthews, K. E., Cook-Sather, A., Godbold, N., Healey, M., \& Rafferty, C. (2020). Learnerteacher partnership in times of COVID-19: A community poll to share practices and perspectives [Online poll]. Brisbane: University of Queensland. Retrieved from https://espace.library.uq.edu.au/view/UQ:66db0d8 